\title{
HOW TO PEREVENT DAMAGES OF TRANSPORTING PIPELINE GIRTH WELDS?
}

\author{
Ahmad Yasser Dakhel \\ PhD student, Institute of Materials Science and Technology, \\ Faculty of Mechanical Engineering and Informatics, University of Miskolc \\ H-3515 Miskolc, Miskolc-Egyetemváros, e-mail: yaser.dakhel@gmail.com
}

\section{János Lukács}

professor, Head of Institute, Institute of Materials Science and Technology, Faculty of Mechanical Engineering and Informatics, University of Miskolc H-3515 Miskolc, Miskolc-Egyetemváros, e-mail: janos.lukacs@uni-miskolc.hu

\begin{abstract}
Girth welds of hydro-carbon transporting pipelines play important role of the life and the lifetime, during both the construction and the operation. In consideration of the huge number of girth welds, the highlighted attention to those is worthy and necessary. The aims of the article are twofold: on the one hand, collecting the influencing factors on the failures of girth welds; on the other hand, answering the question assumed in the title of the article: how to prevent damages of transporting pipeline girth welds? The answers build upon the demonstrated influencing factors, using examples, and systematically respond to those.
\end{abstract}

Keywords: transporting pipeline, girth weld, damage, prevention

\section{Introduction}

Girth welds play important role during both the construction and the operation of the transporting pipelines. Only the high quality girth welds reassure the operators of reliable function of the pipeline systems during their lifetime. Numerous girth welds can be found in different transporting systems, Table 1 summarizes the main characteristics (type, length and number of girth welds) of the Hungarian hydro-carbon transporting systems.

By reason of the huge number of the girth welds the aims of our publication are twofold: on the one hand, collecting the influencing factors on the failures of the girth welds; on the other hand, formulating how to prevent damages of girth welds of pipelines.

Table 1. Main characteristics of the Hungarian hydro-carbon transporting systems

\begin{tabular}{|c|c|c|}
\hline Characteristic & Value & Unit \\
\hline Natural gas system & $\sim 6000$ & $\mathrm{~km}$ \\
\hline Crude oil system & $\sim 850$ & $\mathrm{~km}$ \\
\hline Other systems transporting liquid media & $\sim 1200$ & $\mathrm{~km}$ \\
\hline Total length & $\sim 8050$ & $\mathrm{~km}$ \\
\hline Average length of individual pipe sections & $\sim 11$ & $\mathrm{~m}$ \\
\hline Girth welds & $\sim 732.000$ & item \\
\hline
\end{tabular}




\section{About the girth welds}

Unfortunately, the old pipeline systems often contain girth welds with unacceptable quality. Figure 1 shows two non-Hungarian examples (Anon1, Anon2) where the manufacturing of the welded joints was ineligible.
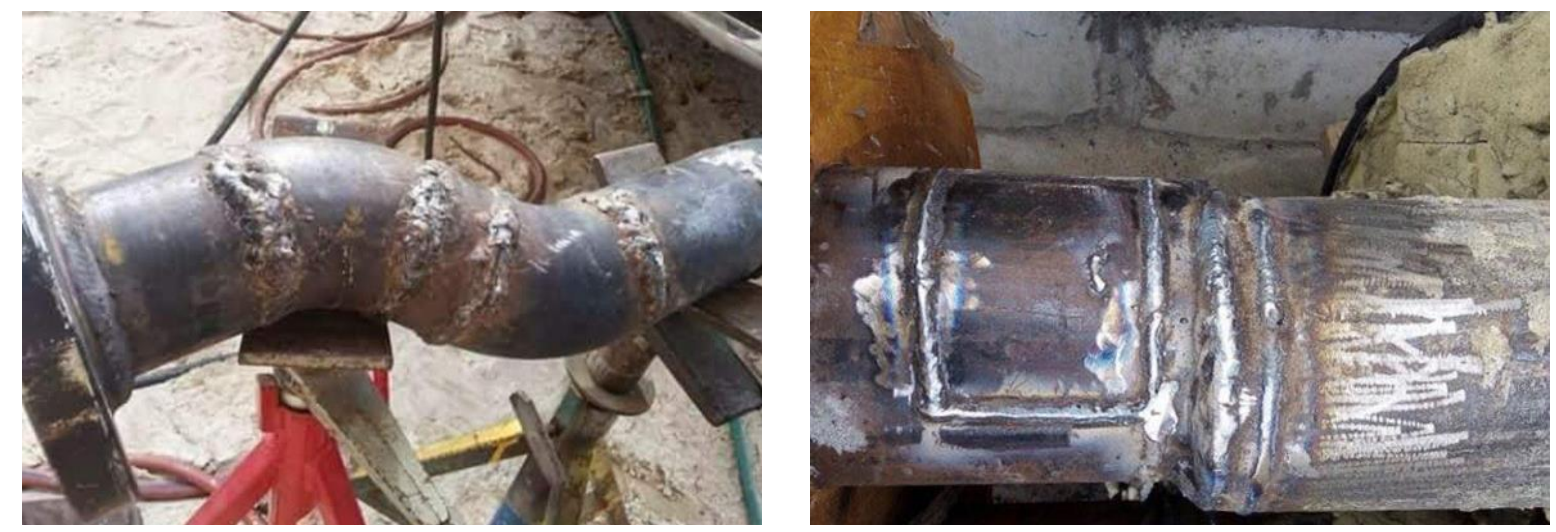

Figure 1. Unacceptable girth weds (Anon1, Anon2).

A study (Eiber and Jones, 1992) summarizes the obligated-to-reports incidents of a 6.5 year research process. Figure 2 shows the cause distribution for all incidents (621 items) and for weld defects (50 items). Based on the Figure 2, it can be stated, that welds are more damageable, as we have no reason to suppose that welds have more favourable position from the point of view of corrosion and external force than the other parts of the pipeline. At the same time, the construction defects and material discontinuities occurs in much higher ratio in welds than in the other parts of the pipelines. According to Hungarian failure statistics significant part of failures were retraceable for weld defects, basically in girth welds. The comparison of the international data and the Hungarian statistics show, both in the past and present, that the ratio of the weld defects in Hungarian transporting pipelines is higher than the above-mentioned one and weld defects typically occur in girth welds.

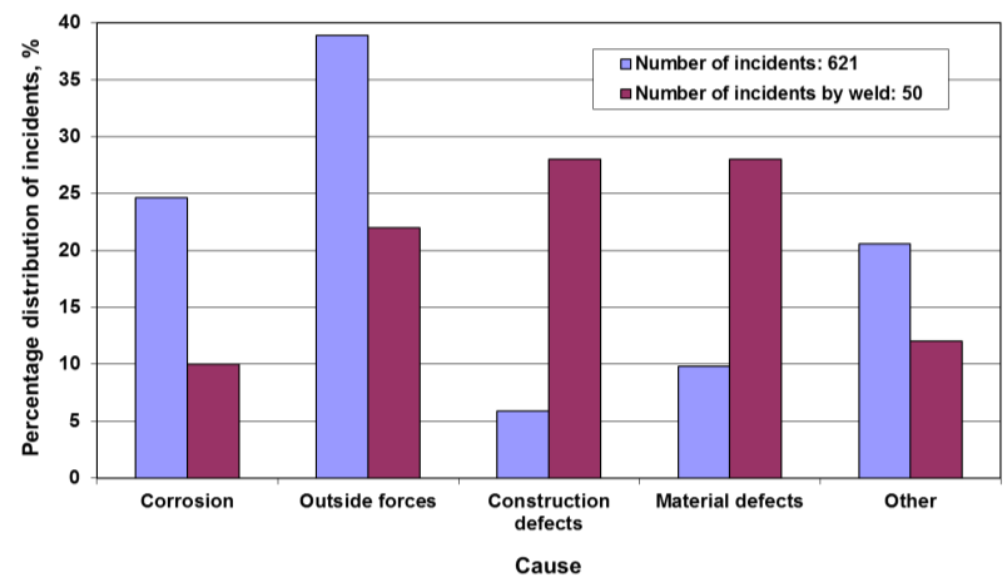

Figure 2. Incident distribution by cause (Eiber and Jones, 1992) 
The different defects of welded joints occurring in the welded structures with high importance can be classified into three groups of acceptability:

- defects acceptable by the assessment rules (workmanship criteria) of welded joints;

- defects unacceptable by the assessment rules of welded joints, but having no influence on the Fitness for Purpose (FfP) or Fitness for Service (FfS) of the welded joint;

- defects influencing the Fitness for Purpose or Fitness for Service of the welded joint.

The three groups require different approaches with special emphasis of girth welds particularities. These characteristics are summarized in Figure 3, whereon the girth weld integrity puzzle demonstrates that the girth weld integrity depends on many factors interacting with each other (Denys, 1999; Nagy, Lukács and Török, 2005).

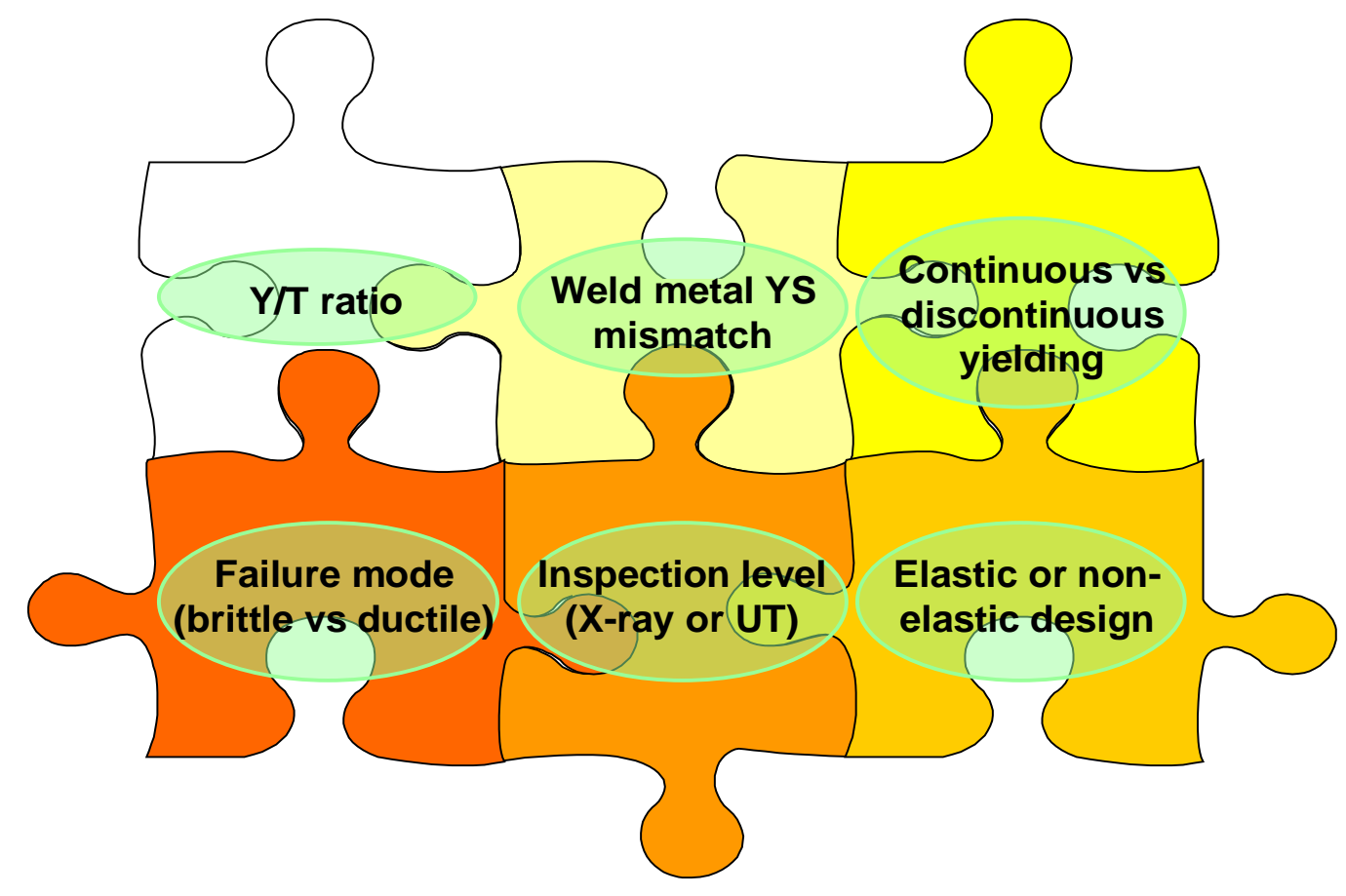

Figure 3. Girth weld integrity puzzle (Denys, 1999; Nagy, Lukács and Török, 2005).

\section{Influencing factors on damages of girth welds}

The influencing factors on damages of girth welds can be divided into three main groups, as follows: design of the pipeline; construction of the pipeline; operation of the pipeline including integrity management.

Either part of the design is the design and designation of the pipeline path and tracing. Especially, the crossings and the different installations have important role. Figure 4 demonstrates the difficulty and the hazardousness of the problem (Anon3). (How do make up the sculptures of the modern age?) 

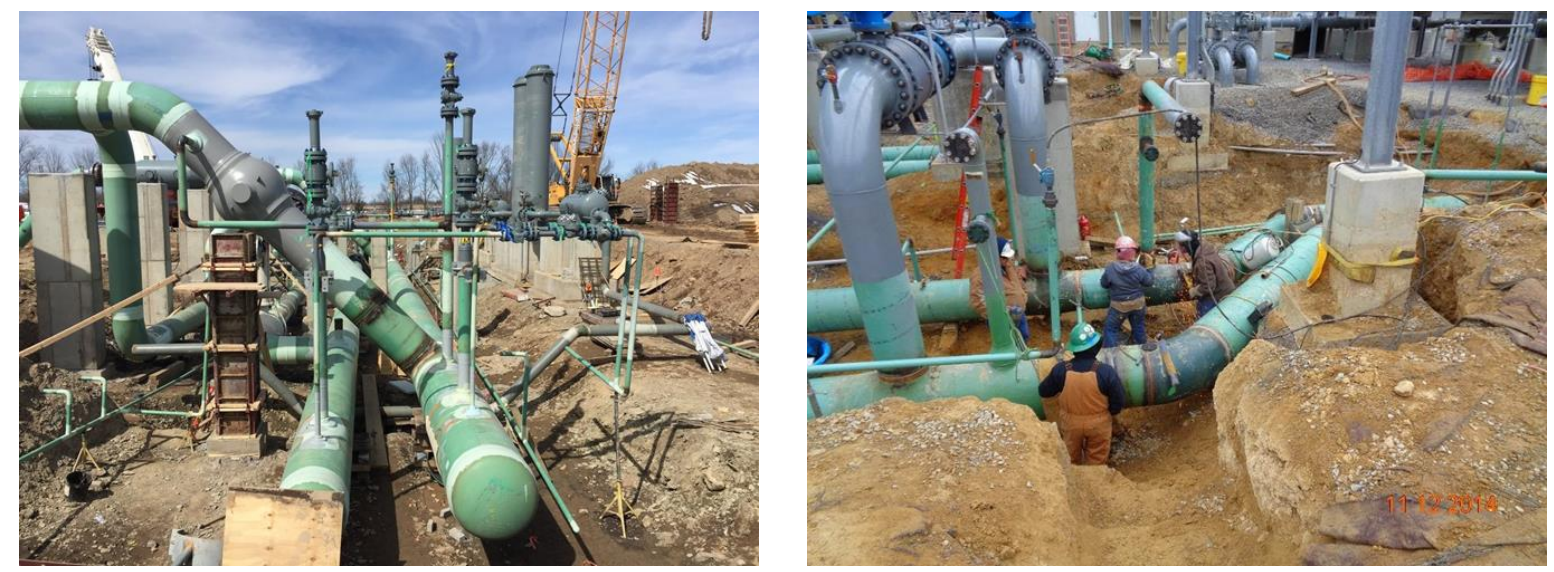

Figure 4. Pipelines and nodes in an installation (Anon3)

Another part of the design is the specification of the welding technology, including the welding of the pipeline and the related facilities. Extraordinary attention should be appropriated for the specification of possible axial misalignment, changing of wall thicknesses etc.

Figures 5-7 illustrate three determining parts of the pipeline construction, the treatment of the axial misalignment (Lee; Sanborn, 2015), the realisation of the laying the pipeline (Lee; Bruce, 2017) and the connection of different section with different characteristics (Lee), respectively. The selected unfavourable examples point out the complexity of the tasks and the problems.
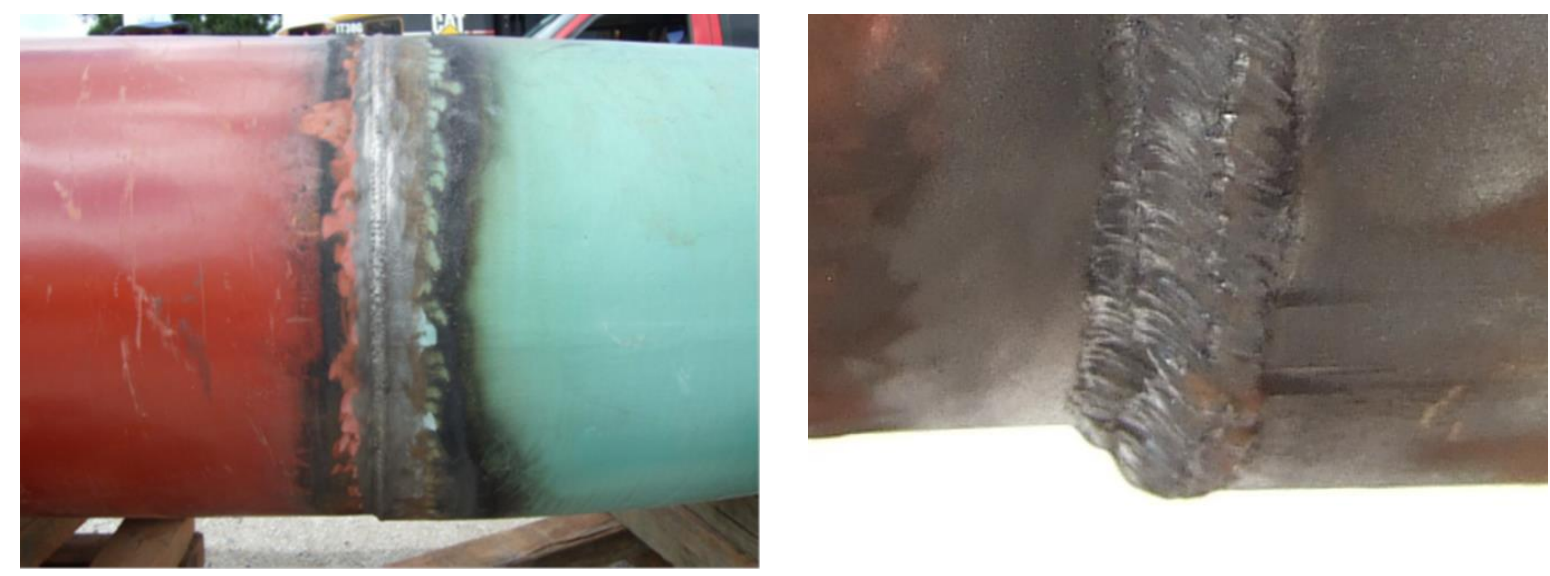

Figure 5. Unacceptable treatment of an axial misalignment (Lee; Sanborn, 2015)

Regarding that welded joints of buried steel transporting pipelines may contain such defects, which have not been detected during the construction or are discovered only during the operation, we must declare about their permissibility and correction. Since failure detection and especially defect correction represents extremely expensive procedures, it is reasonable to complete critical analysis (Engineering Critical Assessment) of effects of flaws. This provides the possibility for minimizing the necessary corrections, so that the risk of further operation should not exceed the acceptable level. 

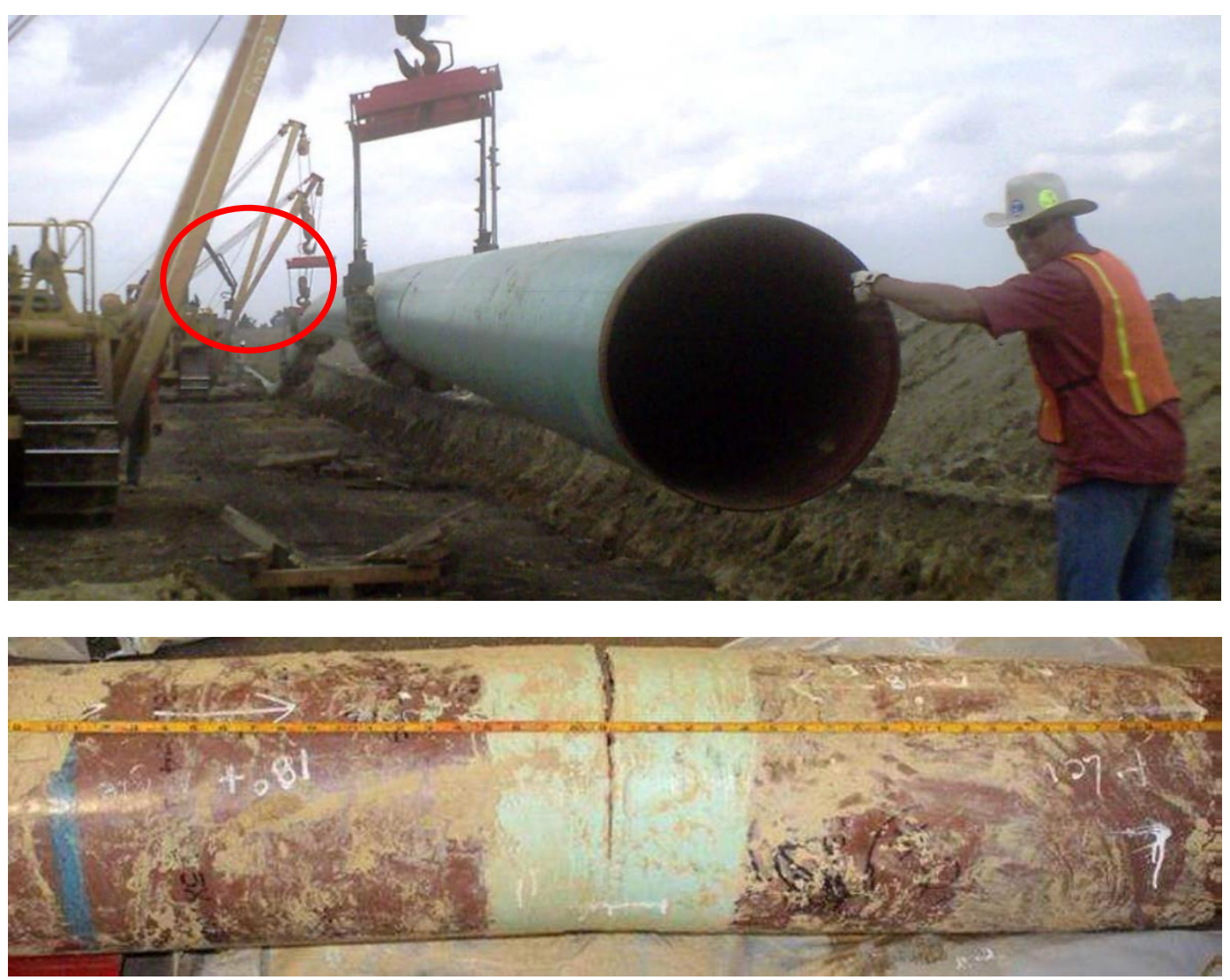

Figure 6. Above: Pipeline laying (Lee); Below: Girth weld crack caused by different pipe and ditch profiles (Bruce, 2017)
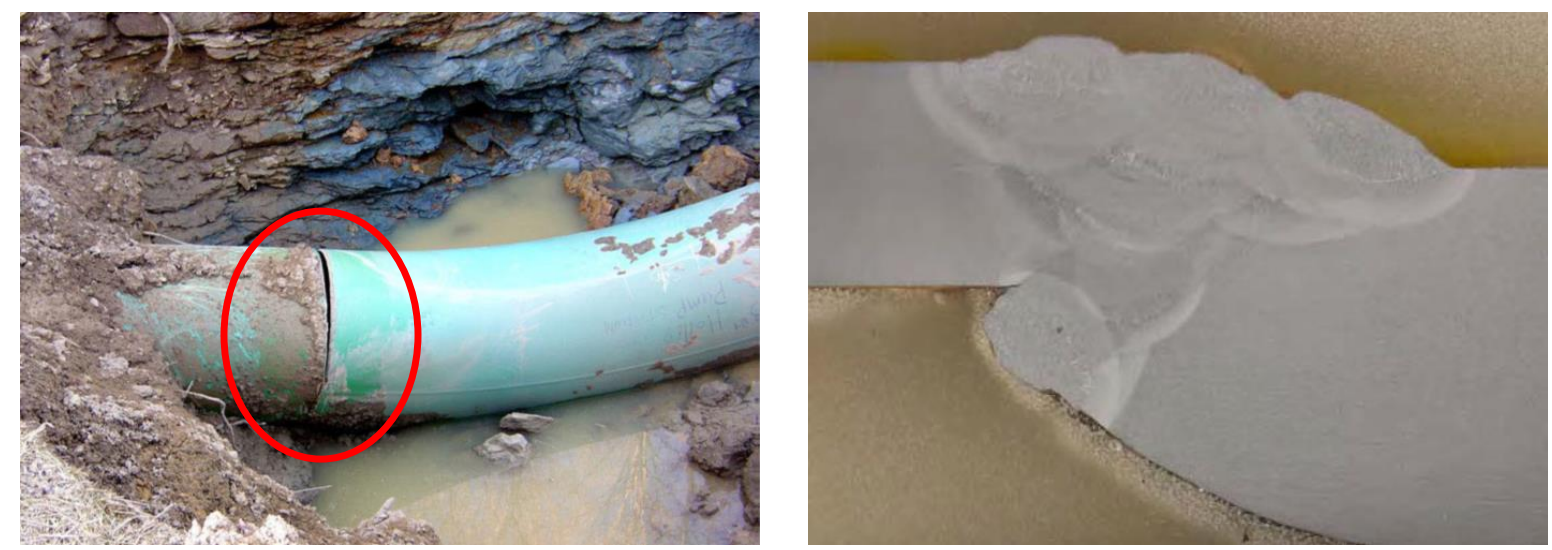

Figure 7. Connection of different pipeline section with different shape and wall thickness (Lee)

The operation and/or integrity management part includes the analysis of the values and the variations of the internal pressure. Figure 8 shows an example using 1.039.753 registered data from a Hun- 
garian pipeline section, where data clearly demonstrates the cyclic loads on the section designed under quasi-static loading conditions.

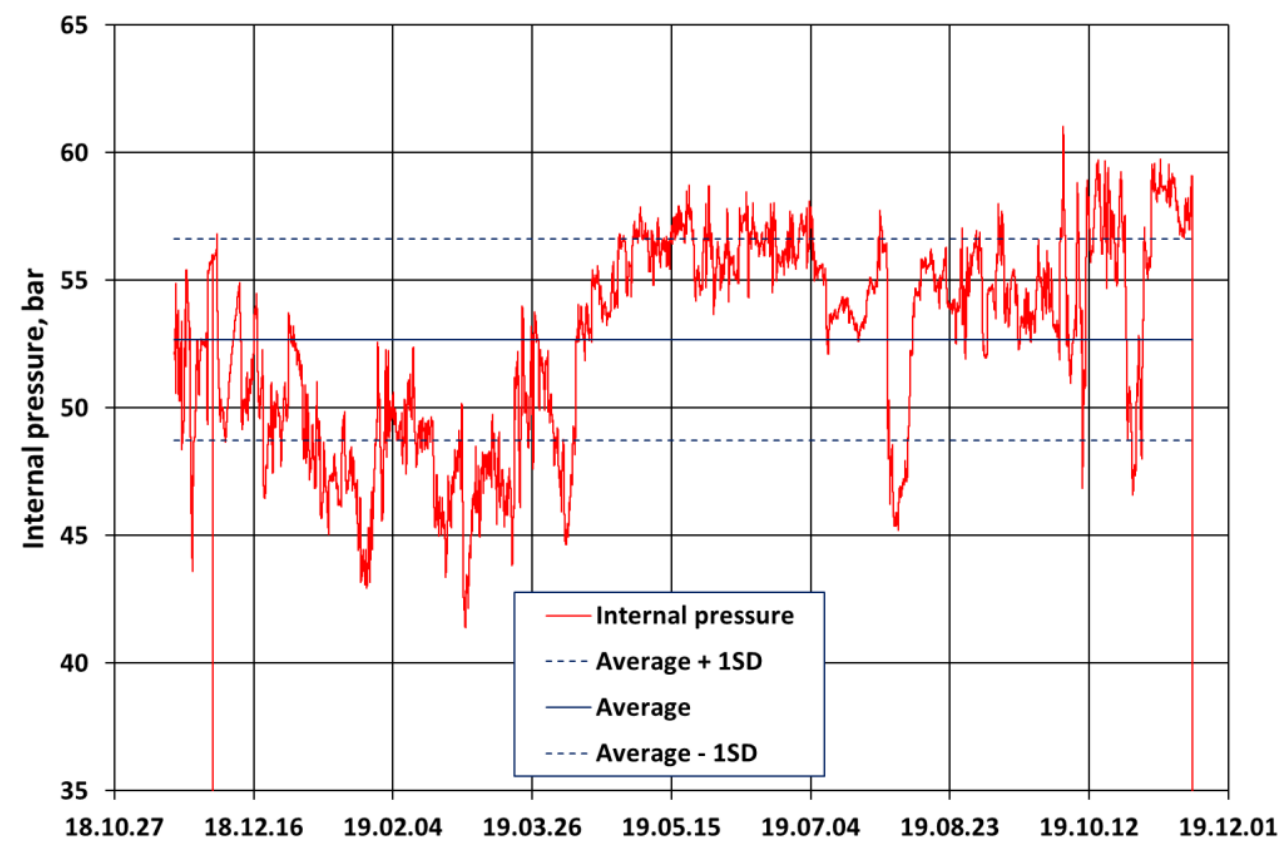

Figure 8. Changing of the internal pressure on a Hungarian gas transporting pipeline section

Important parts of the operating transporting pipeline are the periodic (state) inspection and the continuous (state) control. Since the corrosion defects are the most common metal loss defects and their forms are various, differentiated consideration should be attended to their location, sizes, growth rate etc. Figure 9 shows corrosion defects near and on pipeline (girth and spiral) welds (Feng, 2017; Anon4).
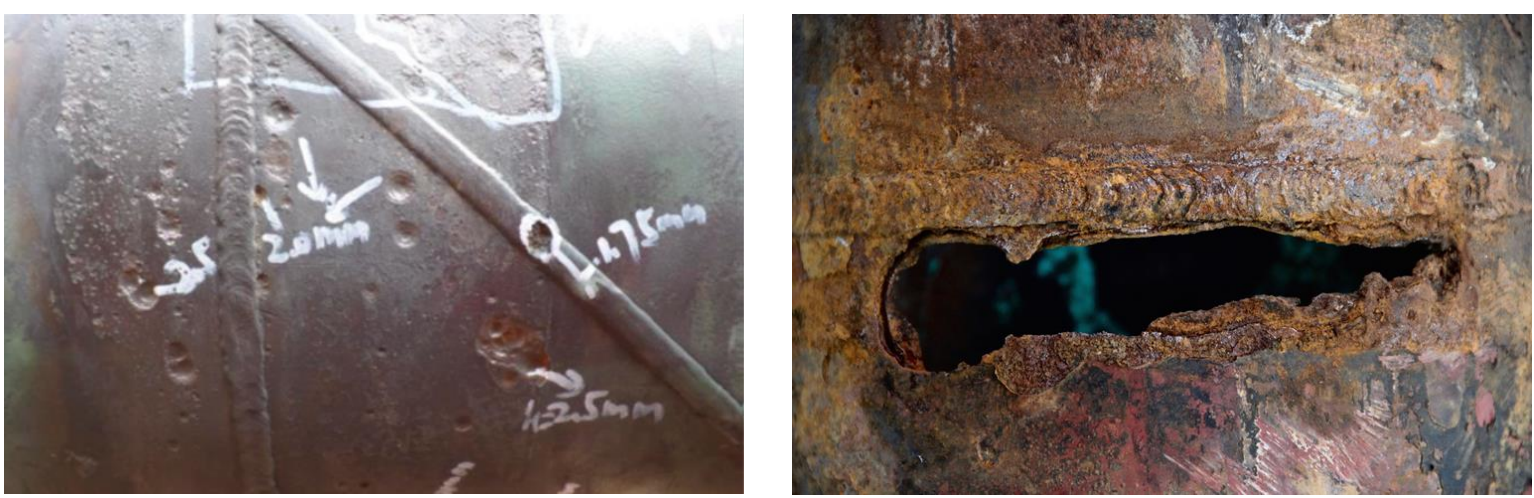

Figure 9. Corrosion defects near and on pipeline welded joints (Feng, 2017; Anon4)

Another corrosion category is the Stress Corrosion Cracking (SCC), with classical terminology, or Environmentally Assisted Cracking (EAC), with more general terminology. Hydrogen play important role in this field and hydrogen damage is a term that covers a range of different types of failure modes, 
including embrittlement (HE), cracking (HIC, HAC etc.) and blistering. Figure 10 a) shows schematically the main hydrogen problems which can occur in steel at normal temperatures, although it must be stressed that not all types can occur simultaneously, or in the same type of steel. The probability of all such forms of hydrogen damages usually increases with increasing strength, although blistering can occur in almost any steels (Francis, 2001). Concurrently, Figure $10 \mathrm{~b}$ ) illustrates the electrochemical potential and $\mathrm{pH}$ regions where SSC can occur for carbon (e.g. pipeline) steels in typical production environments (Iannuzzi, 2011).

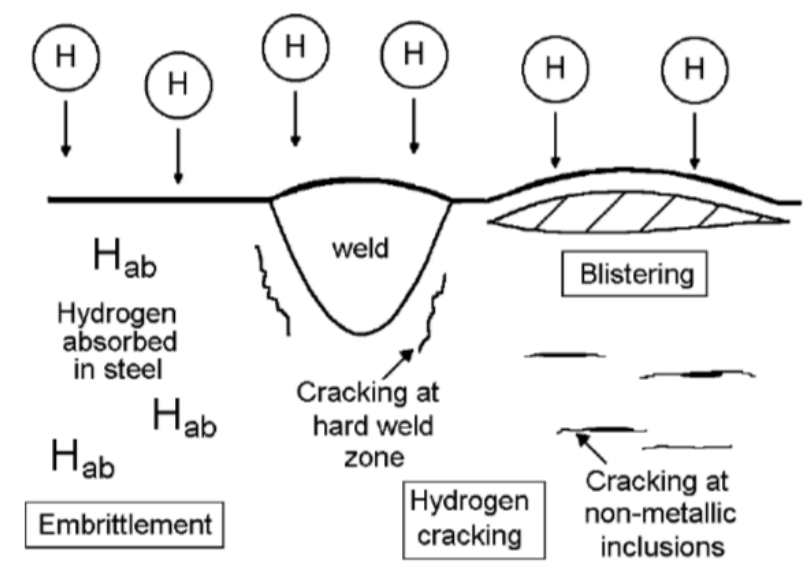

a)

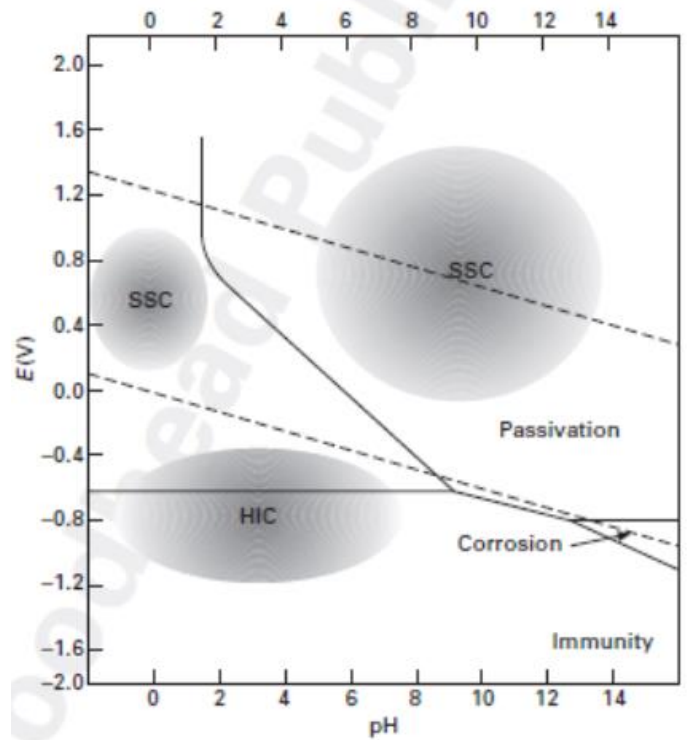

b)

Figure 10. a) Hydrogen embrittlement, cracking and blistering processes (Francis, 2001); b) EAC modes as a function of $\mathrm{pH}$ and electrochemical potential for carbon steel (Iannuzzi, 2011)

Figure 11 shows two circumferentially oriented stress corrosion cracking (C-SCC) either in a pipe body and another in a girth weld (Chua, Alleyne \& Calva, 2017).
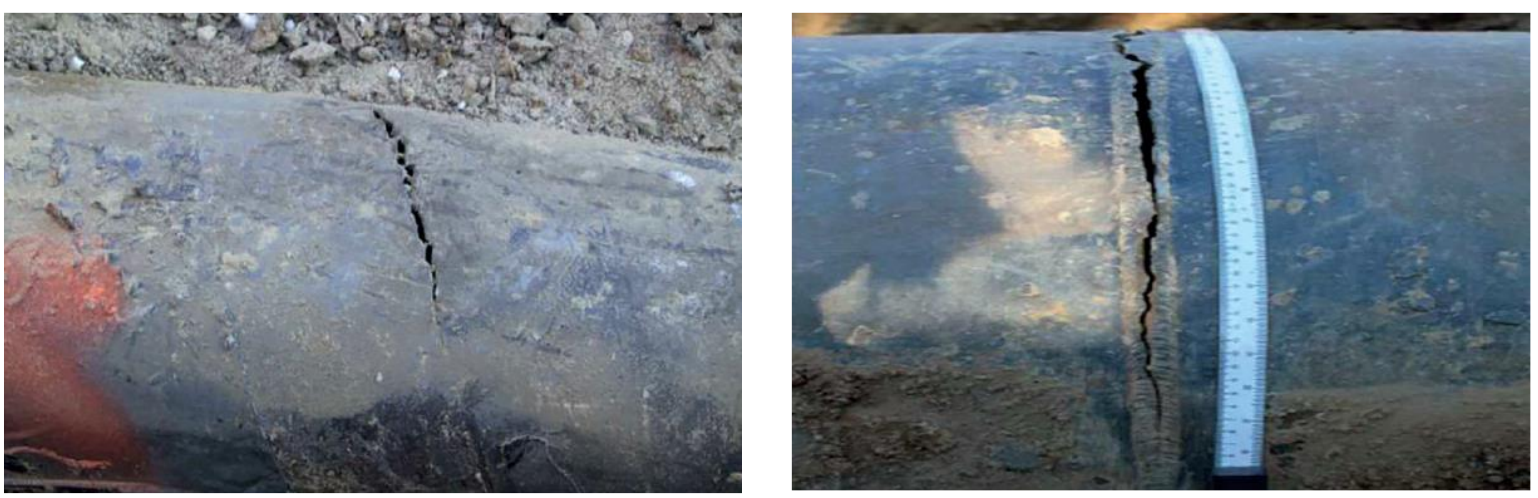

Figure 11. Examples of stress corrosion cracking (Chua, Alleyne \& Calva, 2017) 
At last but not least, the sustainment and reconstruction of the girth weld integrity are continuous tasks of the pipeline operators. Besides the replacing of girth welds, which means making two new girth welds, the reinforcing is an effective way for the improving of the girth weld integrity. Figure 12 shows the results of two full scale fatigue and burst tests of our practice, where the reinforced girth welds with not passed quality have tolerated the loads, the pipe body has been damaged in both cases (Lukács et al., 2012).
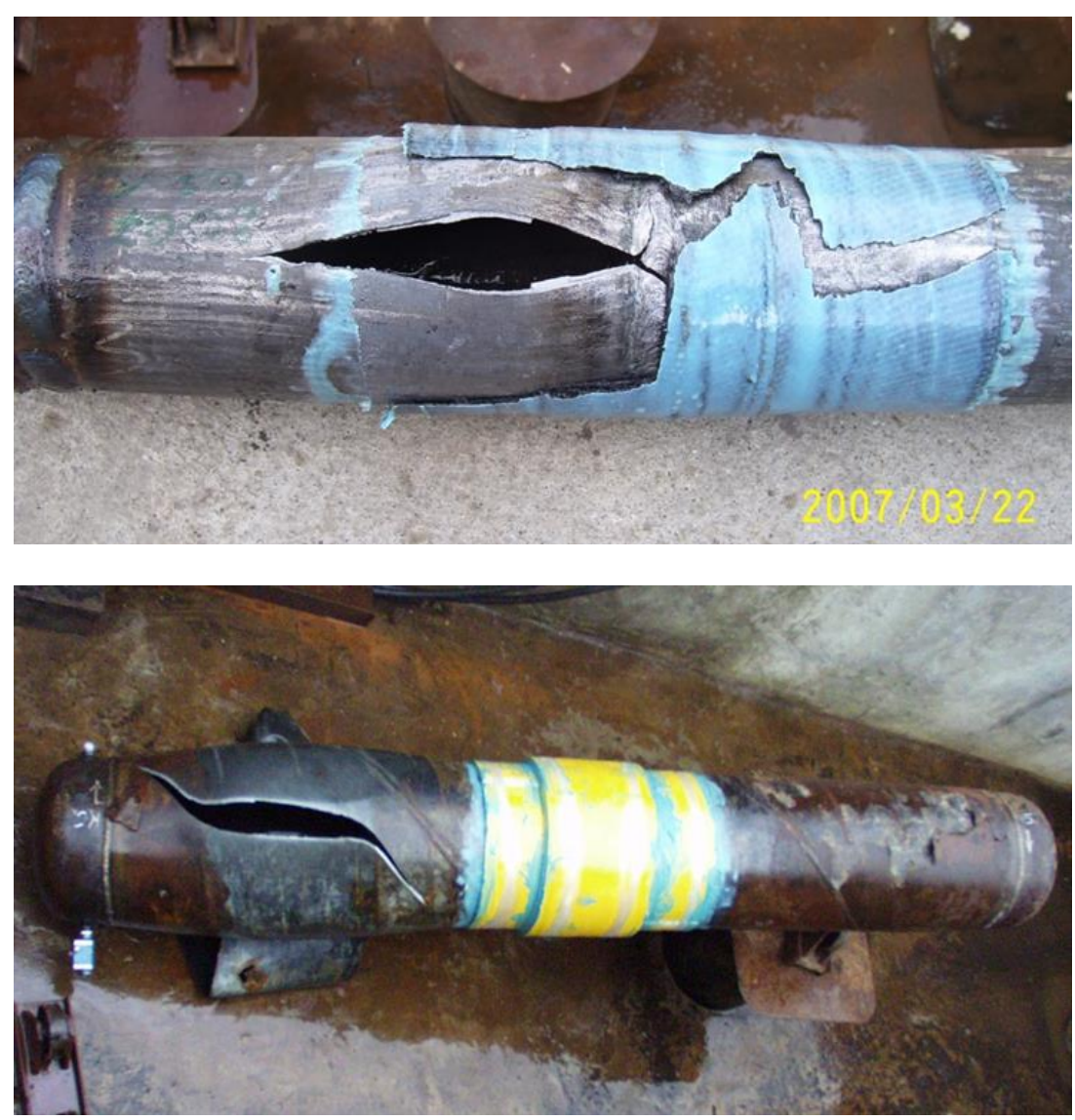

Figure 12. Pipeline sections after fatigue and burst test with reinforced girth weld; Above: Own developed system; Below: Clock Spring repair system (Lukács et al., 2012)

\section{How to prevent damages of transporting pipeline girth welds? - The answers}

Since there are several influencing factors on the damages of pipeline girth welds, there are different possibilities for prevention of the damages, too. These possibilities are as follows:

- observance of the technological discipline and prescriptions

- during the construction,

- during the operation and the maintenance;

- applying Engineering Critical Assessment (ECA) methods, for which

- reflect the operational experiences, 
- demonstrate and endorse the compromise of rational risk and striving for safety ensuring pipeline integrity,

- use the results of the non-destructive examinations, and

- validated by the results of full-scale investigations on different pipeline sections;

- reinforcing of the girth welds using non-welded methods (e.g. composite wraps).

\section{Conclusions}

Girth welds of hydro-carbon transporting pipelines play important role of the life and the lifetime, during both the construction and the operation. Several factors have influence on the behaviour of the girth welds and they can be divided into three main groups, as follows: design of the pipeline; construction of the pipeline; operation of the pipeline including integrity management. In line with these influencing factors, there are different possibilities for the prevention of damages which can be divided into three groups, too, as follows: observance of the technological discipline and prescriptions; applying Engineering Critical Assessment (ECA) methods; reinforcing of the girth welds using non-welded methods.

It should be noted that efficient and cost-effective solutions on whole transporting pipeline systems can only be reached with complex approaches and based on the common works of different expert groups.

\section{References}

[1] Anon1. https://hu.pinterest.com/pin/411235009727724896/ (Last accessed: 17. 03. 2021.)

[2] Anon2. https://www.facebook.com/1594625974172004/photos/pcb.2133261696975093/213 3261173641812/?type $=3 \&$ theater (Last accessed: 17. 03. 2021.)

[3] Eiber, R. J. \& Jones, D. J. (1992). Topical Report on an analysis of reportable incidents for natural gas transmission and gathering lines June 1984 through 1990 to Line Pipe Research Supervisory Committee of the Pipeline Research Committee of the American Gas Association. Battelle, Columbus.

[4] Denys, R. M. (1999). Girth-weld defect qualification methods need to be rationalized. Part 1: Focusing on mechanical properties in Engineering Critical Assessment saves money. Pipe Line and Gas Industry, 82(9) 35-41.

[5] Nagy, Gy., Lukács, J. \& Török, I. (2005). Assessment of Methods in Girth Welds of Steel Pipe$\begin{array}{llll}\text { lines. } & \text { Materials } & \text { 243-248. }\end{array}$ https://doi.org/10.4028/www.scientific.net/MSF.473-474.243

[6] Anon3. https://sites.google.com/site/metroforensics3/pipeline-construction-welding-one-of-theleading-causes-of-pipeline-failure (Last accessed: 17. 03. 2021.)

[7] Lee, K. Y. Challenges with Field Girth Welding. https://primis.phmsa.dot.gov/rd/mtgs/ 071812/kenlee.pdf (Last accessed: 17. 03. 2021.)

[8] Sanborn, J. (2015). Welding -Quality Concerns \& In-Service Welding, October 7th, 2015. https://www.michigan.gov/documents/mpsc/Welding_536247_7.pdf (Last accessed: 17. 03. 2021.)

[9] Bruce, B. (2017). Improving API 1104 for the Twenty-second Edition, API-AGA Joint Committee on Oil and Gas Pipeline Field Welding Practices, January 17-19, 2017 - JW Marriott Austin, Austin, Texas. 
[10] Feng, Q. et al. (2017). Literature Review: Theory and Application of In-Line Inspection Technologies for Oil and Gas Pipeline Girth Weld Defection. Sensors, 17, 50. p. 24; https://doi.org/10.3390/s17010050

[11] Anon4. https://www.ameoilgas.com/corrosion-engineering (Last accessed: 17. 03. 2021.)

[12] Francis, R. A. (2001). Stress Corrosion Cracking And Hydrogen Cracking: Differences Similarities And Confusion. CAP-2001, Paper 052.

[13] Iannuzzi, M. (2011). Environmentally-Assisted Cracking (EAC) in Oil and Gas Production. In: V. S. Raja \& T. Shoji (Eds.), Stress corrosion cracking: Theory and practice, pp. 570-607. Woodhead Publishing Ltd. https://doi.org/10.1533/9780857093769.4.570

[14] Chua, C. A., Alleyne, D. N. \& Calva, M. (2017). Crack growth monitoring using low-frequency guided waves. Insight, 59(2) 64-71, https://doi.org/10.1784/insi.2017.59.2.64

[15] Lukács, J. et al (2012). Selected chapters from structural integrity of engineering structures, J. Lukács (Ed.). University of Miskolc, Miskolc. (In Hungarian.) 